DOE/ER/ $14141--2$

DE92 040336

\title{
ANALYTICAL AND EXPERIMENTAL STUDY OF INSTABILITIES IN BUOYANCY-DRIVEN CONVECTION IN POROUS MEDIA
}

\section{Progress Report}

August 1991 - April 1992

John G. Georgiadis, P.I.

Assistant Frofessor

Department of Mechanical Engineering

Robert Behringer, co-P.I. and Materials Science

Department of Physics

Duke University

Durham, North Carolina 27706

and

G. Allan Johnson, co-P.I.

Professor

Department of Radiology

Duke University Medical Center

Durham, North Carolina 27710

April 1992

PREPARED FOR THE U.S. DEPARTMENT OF ENERGY

UNDER GRANT NUMBER DE-FG05-90ER 14141

DISTRIBUTION OF THIS DOCUMENT IS UNLIMITE 


\section{REPORT OF TECHNICAL PROGRESS}

During the second year of support under the DOE grant, we have made significant progress in two directions: (1) Visualization of structure and flow field in randomly packed beds via Magnetic Resonance Imaging, and (2) Shadowgraphic visualization of natural convection in porous systems. In the following, we describe our activities in detail, cite publications which resulted from this project, and conclude with plans for the last phase of our experimental investigation.

\section{(1) Magnetic Resonance Imaging (MRI).}

The technical details and the full implementation of the phase encoding technique are described in reference [1]. This version of MRI methodology was used to image the structure and velocity profile in the porous media analogue of Poiseuille flow. Since such measurements had not been attempted before, we chose a relatively simple flow before focusing on the natural convection experiments. Our velocity measurements (Figure 1 (a)) reveal the channeling effect (large velocity profile near the tube wall) and the strong correlation between porosity and axial velocity (Figure 7 of reference [1]). We have checked our measurements against the simple parabolic profile for Poiseuille flow of a pure fluid (Figure 1 (b)) with excellent agreement. The water-filled pore space in a packed bed consisting of spherical beads was imaged using 3-D MRI sequences. A superficial examination of volume or cross-sectional images shows a disordered packing (Figure 5 of reference [1] and Figure 2 (b) of this report). However, a thicker slice (normal to the axis of the tube) reveals an ordered structure consisting of concentric circles (Figure 2 (c)). Effectively, this image can be obtained by superimposing a number of thinner slices. We have inverted both images in Figure 2 so that dark denotes water (in the pore space) and light corresponds to the beads (acrylic). Another manifestation of long-range order in the packing appears when the porosity (void fraction) is averaged over each cross-section and is plotted along the axis of the columnar bed. Figure 2 (a) implies that on the average the bed is closely packed. We believe that both effects result from the coarseness of the packed bed (the tube to bead diameter ratio is only ten). Experiments with different coarseness ratios are underway.

\section{DISCLAIMER}

\footnotetext{
This report was preparad as an account of work sponsored by an agency of the United States Government. Neither the United States Government nor any agency thereof, nor any of their employees, makes any warranty, express or impliod, or assumes any legal liability or responsj. bility for the accuracy, completeness, or usefulness of any information, apparatus, product, of process disclosed, or represents that its use would not infringe privately owned rights. Reference hercin to any specific commercial product, procers, or service by trade name, tradernark,

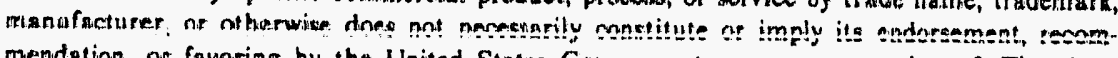
mendation, of favoring by the United States Government or any agency tivereof. The views and opinions of authors expressed herein do not novessarily state or seffect those of the United States Government or any agency thereof.
} 


\section{Poiseuille Flow (pure fluid)}

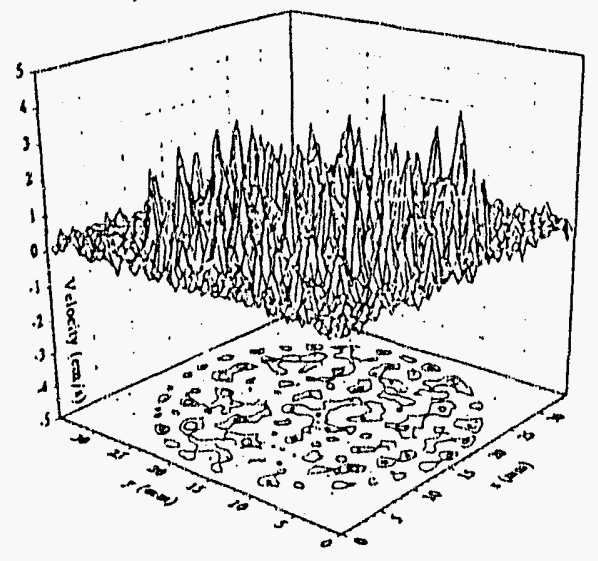

(a)

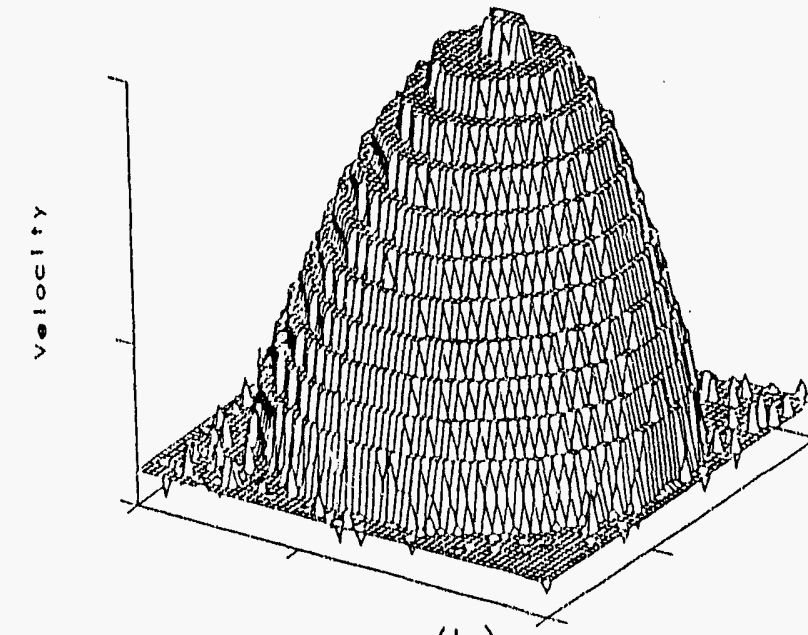

(b)

Figure 1. Axial velocity profiles obtained with MRI in forced flow through straight tube. (a) Flow through packed bed, (b) Pure fluid.

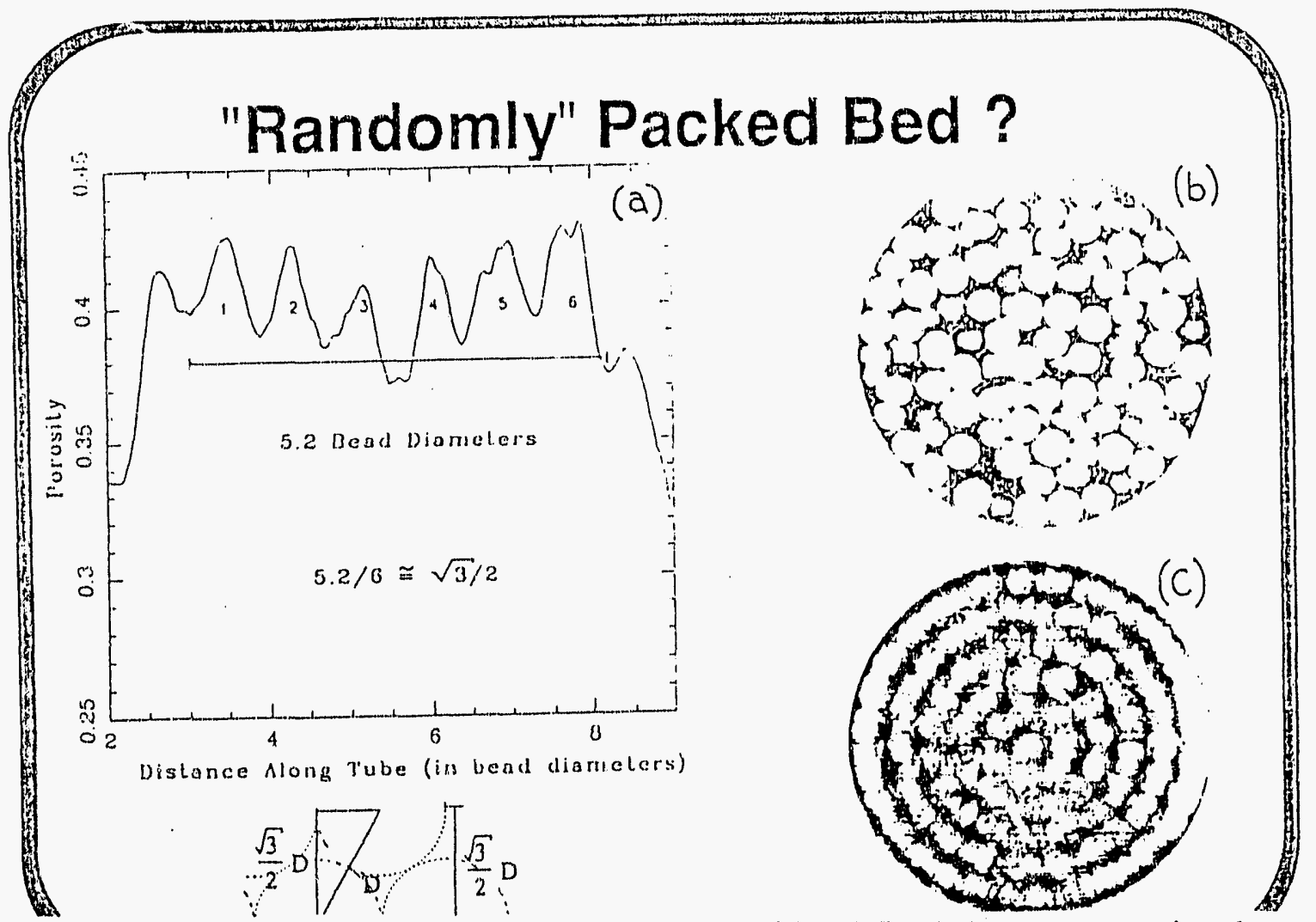

Figure 2. Probing the pore space in packed beds with MRI. (a) Average porosity along the tube axis, (b) thin slice normal to axis, (c) thick slice. 
Our experience with the MRI technique will be indispensable during the experimental investigation of natural convection flow in packed beds. Mr. Mark Shattuck, the Ph.D. candidate who is supported by the D.O.E. grant, has constructed a convection cell made entirely of acrylic and glass so that the MRI signal is not inhibited. For the same reason, careful selection of bonding and sealing materials has been made. A personal computer has been purchased and installed, and the data acquisition system has been set up and debugged.

Mr. Mark Shattuck presented the results of the MRI investigation in two conferences, the ASME Winter Annual Meeting [1] and the American Physical Society Meeting [2]. Dr. John Georgiadis and Dr. Robert Behringer presented some of the results in informal or formal invited seminars.

\section{(2) Shadowgraphic visualization}

The companion to the MRI project has entered its mature phase. A successful experimental investigation of natural convection in a rectangular grid porous layer is reported in reference [3]. In order to examine the robustness of the straight-roll wavepattern, another porous medium configuration was constructed, as depicted in Figure 3. It consists of five parallel acrylic disks stacked on top of each other. Each is perforated with approximately 300 circular holes in a random pattern. The disk diameter is $2.375^{\prime \prime}$, the holes are $0.0625^{\prime \prime}$ in diameter, the disk thickness is $0.0625^{\prime \prime}$ and the spacing between disks is $0.02 "$. This assembly creates a horizontally isotropic porous medium with an average porosity of 0.31 .

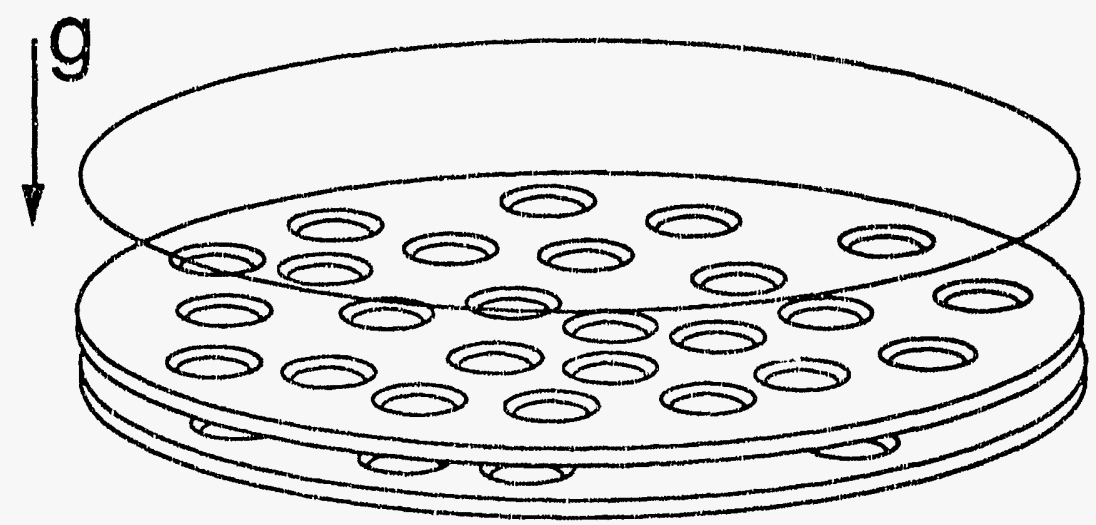

Figure 3. Packed bed with horizontal isotropy. The configuration consists of five equally-spaced perforated disks. 


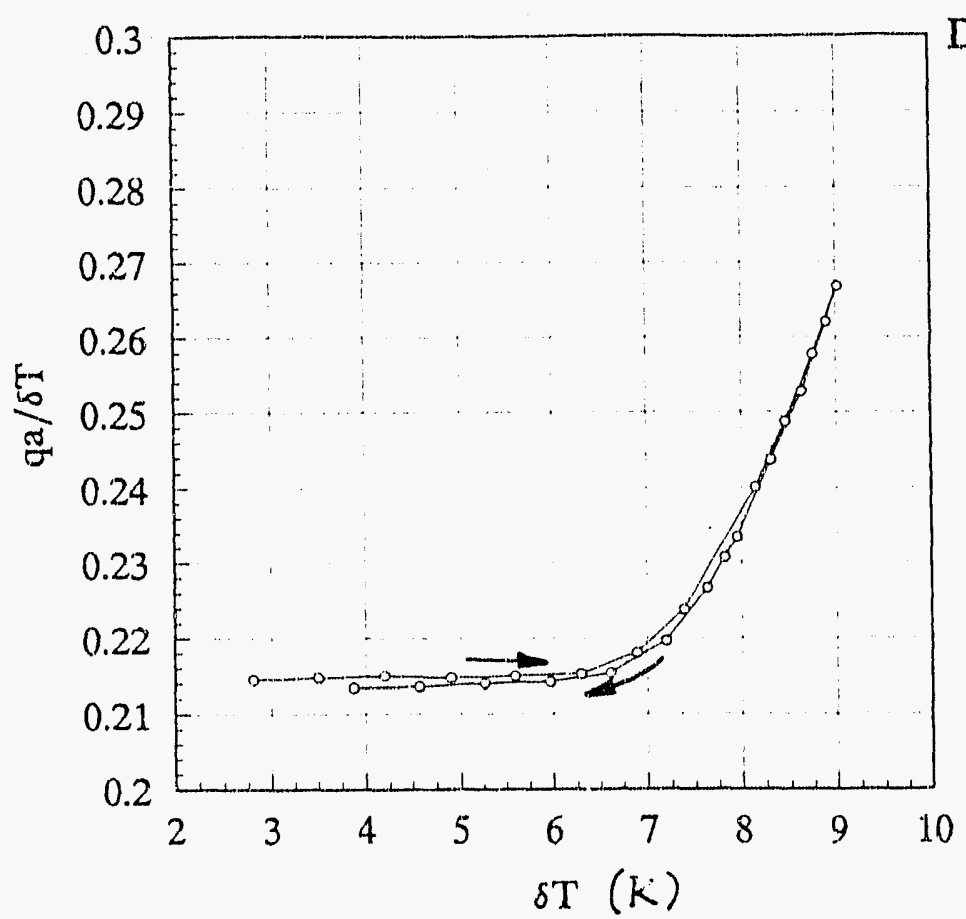

DOE/ER/14141-2

Figure 4. Measured heat transfer in circular disk-porous medium

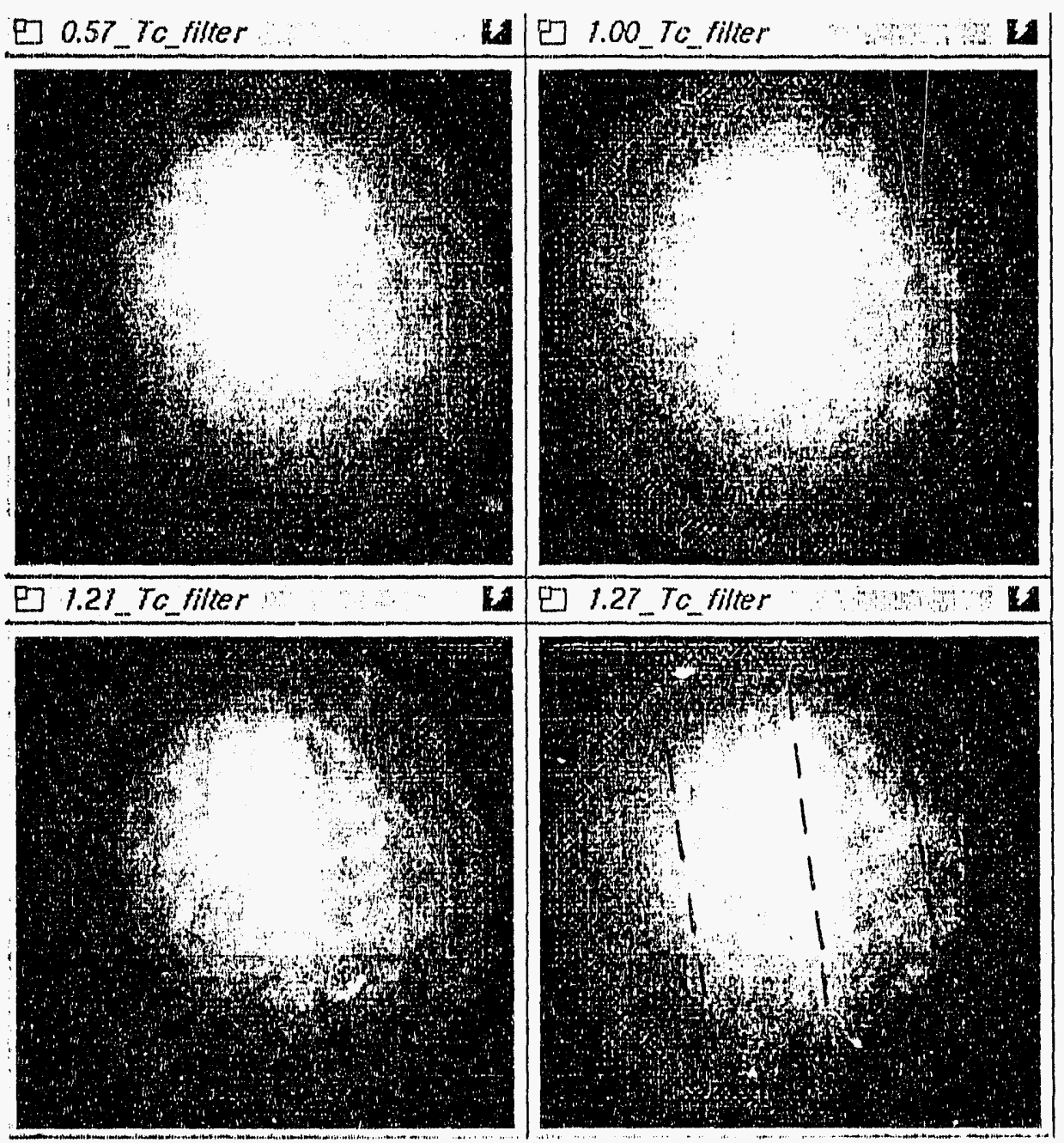

Figure 5. Filtered shadowgraphic images of natural convection. Page 5 
The assembly was positioned inside the cavity of the experimental apparatus depicted in Figure 2 of reference [3] and filled with distilled, degassed and deionized water. A temperature gradient was generated along the gravity vector $\mathrm{g}$. A natural convection experiment was performed following the methodology presented in reference [3]. Figure 4 gives the measured heat transfer coefficient $(q \mathrm{a} / \delta \mathrm{T})$ vs. the temperature difference $\delta \mathrm{T}$ between top and bottom. Notice the high temperature resolution and the almost identical response during increasing and decreasing $\delta \mathrm{T}$ (arrows). The filtered shadowgraphs of Figure 5 (which correspond to view through the top of the cavity) reveal the formation of straight rolls after the onset of convection.

\section{PLANS FOR THE PERIOD MAY 1992-AUGUST 1993}

\section{(1) Magnetic Resonance Imaging}

Cooling and heating reservoirs made of acrylic material are added to the constructed cell of cylindrical cross section. Provision will be made for temperature acquisition in locations outside the MRI coil. The cavity will be filled with acrylic beads and will be fully saturated with water. Visualization of the flow using a variety of MRI sequences, including phase encoding and time-of-flight, will then be attempted. The study of unsteady states above onset is possible by implementing fast MRI acquisition scenarios. Mr. Mark Shattuck has gained a formidable amount of theoretical knowledge and practical experience with alternative MRI sequences during the previous phase of the investigation.

\section{(2) Shadowgraphic visualization}

Experiments with the circular disk transparent porous medium will contirue. We will improve the quality of the images by implementing more sophisticated image processing techniques. This part of the investigation (which is useful at slightly supercritical Rayleigh numbers) will complement the MRI work and will ultimately lead to a complete picture of the ons $t$ and supercritical states of natural convection in porous media. The last phase of this investigation will include study of natural convection in packed beds saturated with binary mixtures. 


\section{PUBLICATIONS}

1. M. Shattuck, R. Behringer, J.G. Georgiadis, and G.A. Johnson, "Magnetic Resonance Imaging of Flow in Porous Media Using Phase Encoding", in Experimental Techniques in Multiphase Flows, ed. T.J. O'Hern \& R.A. Gore, FED-Vol. 125, pp. 39-46, ASME, New York, 1991. Paper presented at the ASME Winter Annual Meeting, Atlanta, Dec. 1-6, 1991.

2. M. Shattuck, J.G. Georgiadis, R. Behringer, and G.A. Johnson, "Local Velocity in Porous Media Flow Using Magnetic Resonance Imaging", 44th Meeting of the American Physical Society - Division of Fluid Mechanics, Scottsdale, AZ, November 1991, Bulletin of the American Physical Society, Vol. 36, No. 10, 1991.

3. L. Howle, J.G. Georgiadis, and R. Behringer "Shadowgraphic Visualization of Natural Convection in Rectangular-Grid Porous Layers", in Proc. National Heat Transfer Conference, Sin Diego, August 9-12, 1992. 

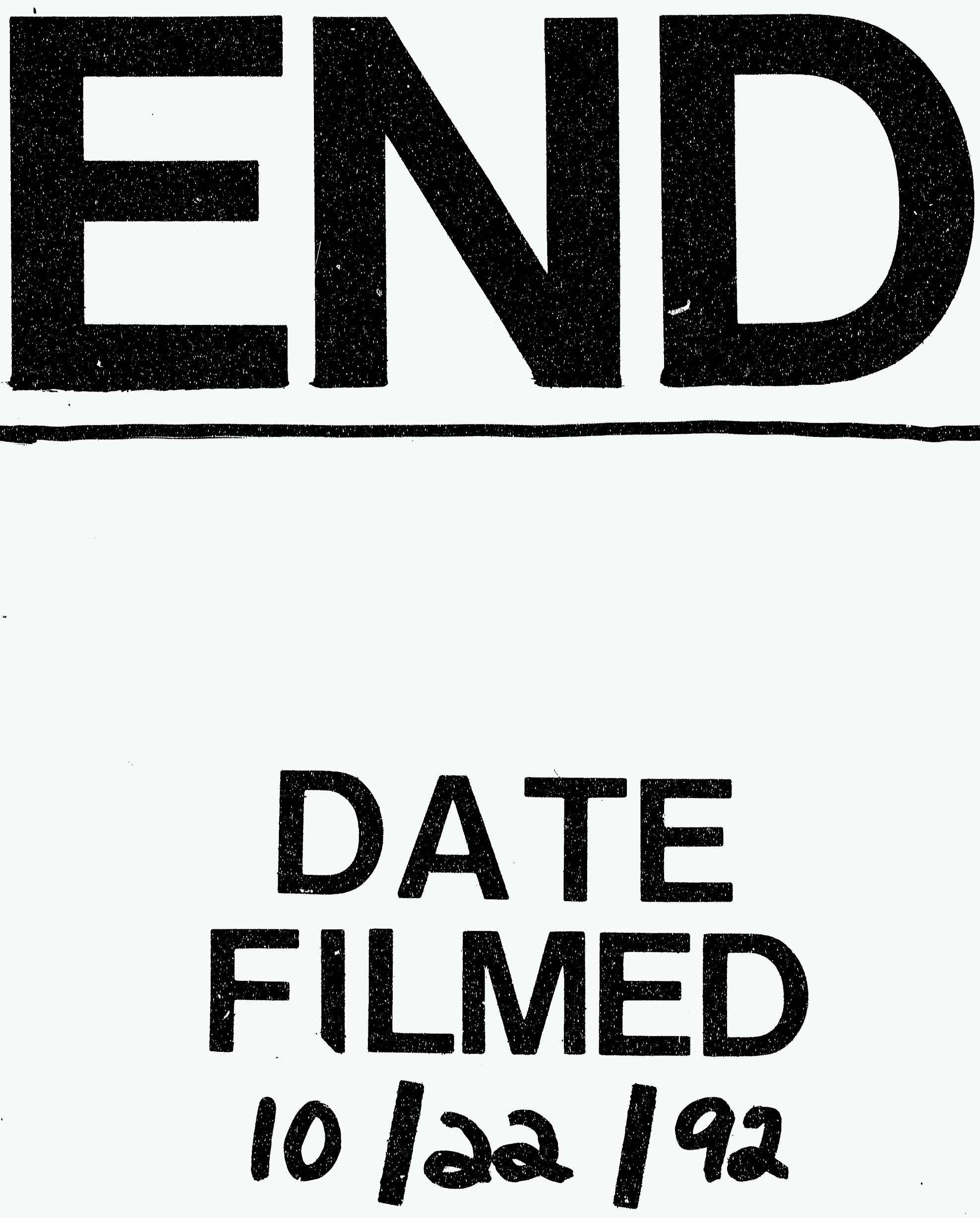


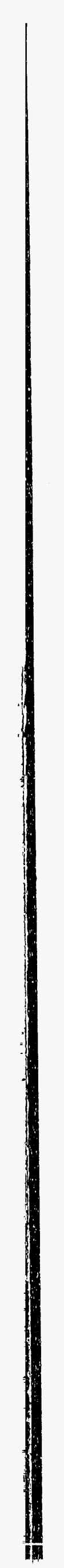

